\title{
Safety and Efficacy of Anterior Lumbar Interbody Fusion for Discogenic Chronic Low Back Pain in a Short-stay Setting: Data From a Prospective Registry
}

\author{
Moira Vieli ${ }^{1}$, Victor E. Staartjes ${ }^{1}$, Hubert A.J. Eversdjik ${ }^{1}$, Marlies P. De Wispelaere ${ }^{2}$, Jan Wolter A. \\ Oosterhuis $^{3}$, Marc L. Schröder ${ }^{1}$
}

1. Neurosurgery, Bergman Clinics, Amsterdam, NLD 2. Miscellaneous, Bergman Clinics, Amsterdam, NLD 3. General Surgery, Haaglanden Medical Center, The Hague, NLD

Corresponding author: Victor E. Staartjes, victor.staartjes@gmail.com

\section{Abstract \\ Introduction}

As a possible treatment option for chronic lower back pain (CLBP) due to single-level degenerative disc disorder (DDD), the efficacy of anterior lumbar interbody fusion (ALIF) has been reviewed various times in the existing literature. Nevertheless, a scarcity of data exists pertaining to ALIF procedures carried out in a short-stay setting using an Enhanced Recovery after Surgery (ERAS) protocol, particularly concerning the safety.

\section{Methods}

Prospectively collected data are analyzed to study the efficacy and safety of short-stay ERAS ALIF in treatment of single-level DDD. Visual Analog Scale (VAS) in both back and leg pain along with the Oswestry Disability Index (ODI) were used to collect measure outcomes. The primary endpoint was a minimum clinically important difference (MCID) of $\geqslant 30 \%$ for the ODI at 12 months.

\section{Results}

Forty-four patients underwent surgery after failed long-term conservative treatment. MCID was achieved in $78 \%$. Age was the only significant factor in association with MCID $(p=0.03)$, while gender, Modic changes, results of prognostic tests, prior surgery and smoking status had no significant influence on either MCID or change scores for any outcome measure. One complication in the form of transient new radiculopathy occurred in one patient (2.3\%).

\section{Conclusion}

Received 07/15/2019 Review began 07/20/2019 Review ended 07/30/2019 Published 08/07/2019

\section{() Copyright 2019}

Vieli et al. This is an open access article distributed under the terms of the Creative Commons Attribution License CC-BY 3.0., which permits unrestricted use, distribution, and reproduction in any medium, provided the original author and source are credited.
With overall positive outcomes in terms of both efficacy and safety, an ALIF procedure with subsequent implementation of an ERAS protocol in a short-stay setting can be an option for strictly selected patients with CLBP. Further study, however, possibly with a larger sample size, would be necessary to substantiate these findings.

Categories: Pain Management, Neurosurgery, Orthopedics

Keywords: outpatient, chronic low back pain, degenerative disc disease, clbp, alif, lumbar fusion, anterior lumbar interbody fusion, short stay, fast-track, eras

\section{Introduction}

Lumbar interbody fusion has been suggested as a treatment option for chronic low back pain (CLBP) associated with single-level degenerative disc disease (DDD) [1-4]. Through the removal of the degenerated disc as a potential pain generator and fusion of the adjacent vertebrae, the surgery aims to reduce hypermobility and microinstability, hence mitigating pain stimuli [1,5-6]. In particular, anterior lumbar interbody fusion (ALIF) has been highlighted as a promising surgical technique, since the minimum clinically important difference (MCID) in patient-reported outcomes (PROMs) can be achieved with minimal blood loss and relatively short surgical times [1-4].

The surgical treatment of CLBP due to DDD through lumbar fusion has been controversial, as it has been suggested that surgical therapy is not necessarily better than conservative therapy in the general patient population [7]. However, it has been observed that through thorough patient selection, the chances of successful treatment with interbody fusion are substantially improved, indicating that there are in fact subsets of patients that truly profit from surgery [1,8]. Especially a positive outcome of the Pantaloon Cast Test (PCT), a cast worn for a certain period of time to increase stability and therefore imitate a spinal fusion, 


\section{Cureus}

has served as a suitable prognostic test in determining likely successful surgery in patients who have not improved through long-term conservative therapy $[1,8]$.

Although there have been quite a few studies published on ALIF for CLBP, there is still a shortage of data regarding the safety of short-stay and outpatient ALIF procedures [9]. Enhanced recovery after surgery (ERAS) protocols [10] have also only been scarcely applied to ALIF [11-12]. Questions may be asked on outcomes and complication rates of carrying out such procedures in these settings [9]. Hence, using data from a prospective registry, we aim to evaluate the safety and efficacy of ALIF for single-level DDD in a short-stay setting, as well as to identify predictors of surgical success.

\section{Materials And Methods}

\section{Overview}

From a prospective registry, all patients who underwent elective ALIF for single-level DDD were identified. All patients were operated between March 2012 and February 2019 in a multidisciplinary team including a neurosurgeon (M.L.S.) and access surgeon (J.W.A.O.) at a specialized short-stay spine surgery clinic. Patients underwent ALIF according to the modified technique by Brau as described previously [1]. An ERAS protocol [9] was applied to improve rehabilitation after surgery, consisting of among others a strict preoperative screening and counseling for suitability of surgical treatment in this setting, thorough preoperative patient education, use of a mini-open technique and autologous cell saver transfusion, limited use of muscle relaxants during surgery, intraoperative avoidance of hypothermia, hypotension, and fluid disbalance, effective and early postoperative analgesia, early guided mobilization and elastic bracing, no restriction on activities of daily living (ADL) postoperatively, and regular, systematic audits [9,13-14] (Table 1).

\begin{tabular}{|c|c|c|c|}
\hline Timepoint & Element & Summary & Discipline \\
\hline \multicolumn{4}{|c|}{ Preoperative } \\
\hline 1 & $\begin{array}{l}\text { Control of smoking and alcohol } \\
\text { intake }\end{array}$ & $\begin{array}{l}\text { Advice to cease smoking and excessive alcohol intake before surgery; } \\
\text { Cessation of smoking } 3 \text { months before fusion surgery }\end{array}$ & Neurosurgeon \\
\hline 2 & Strict patient screening & $\begin{array}{l}\text { Strict anesthesiologic screening and patient selection to enhance } \\
\text { perioperative patient safety by targeted optimization of comorbidities }\end{array}$ & Anesthesiologist \\
\hline 3 & Weight loss in obese patients & Structured nutritional advice and counseling for patients with a BMI > 30 & Multidisciplinary \\
\hline 4 & Patient education & $\begin{array}{l}\text { Systematic education on what to expect during recovery. Three simple } \\
\text { principles of conduct are provided ("Three Golden Rules") }\end{array}$ & Neurosurgeon \\
\hline 5 & Prophylaxis against infection & Prophylaxis using a broad-spectrum antibiotic & Anesthesiologist \\
\hline 6 & Prophylaxis against thrombosis & Prophylaxis using low molecular weight heparin & Anesthesiologist \\
\hline \multicolumn{4}{|c|}{ Intraoperatıve } \\
\hline 7 & $\begin{array}{l}\text { avoidance of long-acting } \\
\text { opioids }\end{array}$ & $\begin{array}{l}\text { General anesthesia was maintained using propotol and a short-acting } \\
\text { opioid }\end{array}$ & Anesthesiologist \\
\hline 8 & Local analgesia & Infiltration of the surgical site with local analgesic agents, when applicable & Neurosurgeon \\
\hline 9 & $\begin{array}{l}\text { Minimally-invasive surgical } \\
\text { techniques }\end{array}$ & $\begin{array}{l}\text { approaches, large incisions and therefore damage to muscles can be } \\
\text { reduced }\end{array}$ & Neurosurgeon \\
\hline 10 & Limited use of muscle relaxants & $\begin{array}{l}\text { Muscle relaxants were only sparingly used to enable more efficient } \\
\text { mobilization and recovery }\end{array}$ & Anesthesiologist \\
\hline 11 & $\begin{array}{l}\text { Prevention of fluid dysbalance } \\
\text { and blood transfusion }\end{array}$ & $\begin{array}{l}\text { Over- or underhydration was minimized, vasopressors were administered } \\
\text { to regulate blood pressure, and autologous cell-saver transfusion was } \\
\text { available during all procedures }\end{array}$ & Anesthesiologist \\
\hline 12 & Prevention of hypothermia & Body temperature was controlled using warm air blankets & Anesthesiologist \\
\hline \multicolumn{4}{|c|}{ Postoperative } \\
\hline 13 & $\begin{array}{l}\text { Sparıng use and early removal } \\
\text { of surgical site drains and } \\
\text { urinary catheters }\end{array}$ & $\begin{array}{l}\text { Surgical site drains were only used atter mini-open decompression or Ml- } \\
\text { PLIF. Both drains and catheters were removed as early as possible }\end{array}$ & Multidisciplinary \\
\hline 14 & Opioid-sparing analgesia & Eftective analgesia was achieved usıng NSAIDs and paracetamol. Patıent- & Multidisciplinary \\
\hline
\end{tabular}




\section{Cureus}

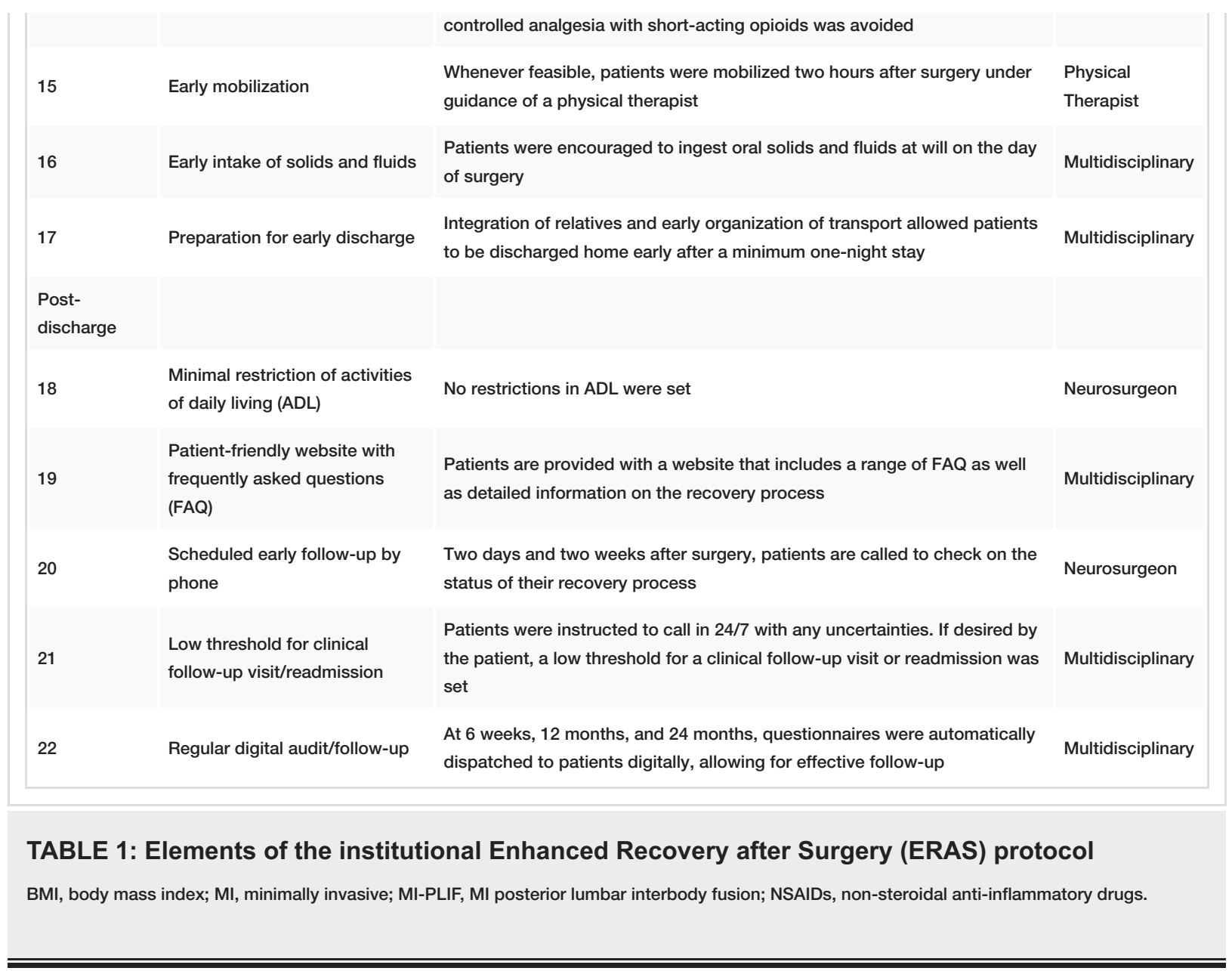

\section{Ethical considerations}

This institutional registry was approved by the local institutional review board (Medical Research Ethics Committees United, Registration Number: W16.065), and this study was performed according to the Declaration of Helsinki. All individual patients in this study provided written informed consent. This study was compiled according to the Strengthening the Reporting of Observational Studies in Epidemiology (STROBE) statement [15].

\section{Patient selection}

Only patients with single-level DDD on magnetic resonance imaging (MRI) presenting with severe, intractable low back pain were considered for ALIF. The decision of a minimally invasive posterior versus anterior approach was made based upon suitable index levels, the desire to avoid the risk of impaired fertility due to the potential complication of retrograde ejaculation, and absence of spondylolisthesis. To be considered for surgical treatment, patients had to have completed $\geqslant 6$ months of unsuccessful conservative treatment. Unless failed back surgery syndrome (FBSS) after at least two prior surgeries at the index level was present, patients had to undergo pantaloon cast testing (PCT) for two weeks, with a $\geqslant 50 \%$ improvement in back pain over at least 14 days to be considered for surgery $[1,8,16]$. Provocative discography and disco-block were not regularly used $[1,17-21]$. Modic type endplate changes were routinely captured, but had no influence on surgical decision-making.

\section{Preoperative anesthesiologic screening}

We applied strict selection criteria for patients considered for surgical treatment [22-23]. A very thorough anesthesiologic screening was carried out for all patients. Patients aged $>80$ or with a body mass index (BMI) $>35$, or American Society of Anesthesiologists (ASA) score >2 were not eligible for surgery [24]. These limitations are dictated by the local insurance policy. Sleep Apnea Syndrome was also a contraindication for surgery. Patients on anticoagulants were never considered for surgery in our setting. This is due to the often-associated comorbidities, and the risk of major bleeding, which represent a high surgical risk without having intensive care unit (ICU) facilities as a back-up. However, patients who were solely on acetylsalicylic acid were considered, and were allowed to continue medication perioperatively. Strict blood pressure regulation was maintained. Patients with hypertension at the preoperative screening were required to consult with their general practitioner or cardiologist to regulate blood pressure before being considered for surgery. Patients were required to cease smoking before being scheduled for fusion surgery. Osteoporosis 
was a contraindication for fusion procedures [25]. Patients who presented with a higher risk profile than delineated by our screening thresholds were always referred to larger, academic or community hospitals.

\section{Perioperative management}

Preoperatively, patients received cefazolin (2000 mg) as antibiotic prophylaxis, and general anesthesia was maintained using propofol and sufentanil. The use of muscle relaxants was limited to allow for faster recovery. Autologous cell-saver transfusion was available during all procedures [26]. Postoperatively, analgesia was maintained and adjusted as appropriate. All patients were mobilized early on the day of surgery under the guidance of a licensed physiotherapist and were discharged home as soon as they were able to climb stairs. Patients were provided with a light elastic brace. No restrictions on ADL were made, and patients were instructed to contact the center with any uncertainties. Patients were seen for a six-week and one-year follow-up.

\section{Data collection}

Patients completed a standardized questionnaire containing a visual analogue scale (VAS) for back pain and leg pain severity, and a validated Dutch version of the Oswestry Disability Index (ODI) as a measure of functional disability. The ODI at 12 months was defined as the primary endpoint. Patients filled in paperbased questionnaires at baseline. At six weeks and 12 months after surgery, scheduled follow-up questionnaires were obtained during the subsequent visits. All complications were systematically collected in a separate database, and reoperations were tracked.

\section{Statistical analysis}

Continuous data are given as mean \pm standard deviation, and categorical data as numbers (percentages). Clinical success was defined as reaching the MCID of $\geqslant 30 \%$ improvement in ODI - the primary endpoint of this study - from baseline to the 12-month follow-up [27]. Mann-Whitney U and $\chi 2$ tests were performed to assess intergroup differences, depending on the data type. Intra-subject longitudinal data were assessed using Wilcoxon's signed-rank test. All analyses were carried out using R version 3.5.1 (The R Foundation for Statistical Computing, Vienna, Austria). A 2 -tailed $\mathrm{p} \leqslant 0.05$ was considered statistically significant.

\section{Results}

\section{Patient characteristics}

In total, 44 patients were operated upon. The cohort included 15 (33\%) male and 30 (67\%) female patients, with the average age being 40.8 years, ranging from 19 to 62 years (Table 2). 


\section{Cureus}

Parameter

Age, mean \pm SD [yrs.]

Male gender, n (\%)

Modic type endplate changes, n (\%)

None

1

Single-level DDD, n (\%)

Received PCT, n (\%)

Positive PCT, n (\%)

Prior surgery, n (\%)

Active smoker, n (\%)

Height, mean \pm SD $[\mathrm{m}]$

Weight, mean \pm SD $[\mathrm{kg}]$

BMI, mean $\pm S D\left[\mathrm{~kg} / \mathrm{m}^{2}\right]$

History of back pain, mean \pm SD [mos.]

Index level, $\mathrm{n}(\%)$

L3-L4

L4-L5

L5-S1

L4-S1

Baseline PROMs, mean \pm SD

VAS Back Pain

VAS Leg Pain

ODI
Value $(\mathrm{N}=44)$

$40.8 \pm 8.8$

15 (33)

$8 / 39(20)$

23/39 (59)

$8 / 39$ (20)

$30 / 39$ (77)

33 (73)

$31 / 33(96)$

$17 / 40$ (43)

12/41 (29)

$1.77 \pm 0.099$

$76 \pm 11.4$

$24.3 \pm 2.6$

$11.2 \pm 3.5$

1 (2)

23 (51)

20 (42)

1 (2)

$71.8 \pm 19.5$

$42.9 \pm 28.4$

$49.1 \pm 14.6$

\section{TABLE 2: Summary of patient demographics}

SD, standard deviation; DDD, degenerative disc disease; PCT, pantaloon cast test; BMI, body mass index; PROM, patient-reported outcome measure; VAS, visual analogue scale; ODI, Oswestry Disability Index.

\section{Efficacy}




\section{Cureus}

Parameter

Value $(\mathrm{N}=44)$

6-week PROM scores, mean \pm SD

VAS Back pain

$32.7 \pm 22.4$

VAS Leg pain

$23.9 \pm 30.5$

ODI

$29.5 \pm 18.4$

12-month PROM scores, mean \pm SD

VAS Back pain

$31.4 \pm 26.8$

VAS Leg pain

$17.9 \pm 22.8$

ODI

$20.1 \pm 18.2$

12-month change score from baseline, mean $\pm S D$

VAS Back pain

$42.6 \pm 30.5$

VAS Leg pain

$20.7 \pm 32.8$

ODI

$28.5 \pm 22.7$

MCID, n (\%)
$21 / 27(78)$

\section{TABLE 3: Short- and long-term outcome measures}

SD, standard deviation; VAS, visual analogue scale; ODI, Oswestry Disability Index; MCID, minimum clinically important difference.

Twenty-seven patients (61\%) had full data on baseline and 12-month PROMs. Clinical success was met in 21 patients, while it was not achieved in 6 patients, resulting in a clinical success rate of $78 \%$ (Table 3).

No differences were found regarding gender, age, presence of Modic changes, prior surgery or smoking status (Table 4). 


\section{Cureus}

\begin{tabular}{|c|c|c|c|}
\hline \multirow[b]{2}{*}{ Parameter } & \multicolumn{3}{|l|}{ MCID } \\
\hline & $\mathrm{NO}(\mathrm{N}=6)$ & YES $(N=21)$ & $\mathrm{P}$ \\
\hline Gender, n (\%) & & & 1.0 \\
\hline Male & $2(33)$ & $7(33)$ & \\
\hline Female & $4(67)$ & $14(67)$ & \\
\hline Age, n (\%) & & & 0.27 \\
\hline$>45$ & $0(0)$ & $7(33)$ & \\
\hline$\leq 45$ & $6(100)$ & $14(67)$ & \\
\hline Modic Changes, n (\%) & & & 1.0 \\
\hline Yes & $4(67)$ & $15(71)$ & \\
\hline No & $1(17)$ & $4(19)$ & \\
\hline Prior surgery & & & 0.32 \\
\hline Yes & $2(33)$ & $9(43)$ & \\
\hline No & $3(50)$ & $11(52)$ & \\
\hline Discography, n (\%) & & & 0.62 \\
\hline Positive & $4(67)$ & $12(57)$ & \\
\hline Negative & $0(0)$ & $3(14)$ & \\
\hline Smoking Status, n (\%) & & & 1.0 \\
\hline Smoker & $2(33)$ & $6(29)$ & \\
\hline Non-Smoker & $3(50)$ & $14(63)$ & \\
\hline
\end{tabular}

TABLE 4: Analysis of factors potentially associated with MCID in the primary endpoint

${ }^{*} p \leq 0.05$

MCID, minimum clinically important difference.

:Table 5 lists all factors that were tested in association with PROM change scores. Out of all factors, only the association of age with ODI change score was proven to be statistically significant $(\mathrm{p}=0.03)$, showing greater change scores in patients above the age of 45 . Apart from that, neither gender, Modic changes, prior surgery or smoking status had an influence on the PROM change scores. 


\section{Cureus}

\begin{tabular}{|c|c|c|c|c|c|c|}
\hline \multirow[t]{3}{*}{ Parameter } & \multicolumn{6}{|c|}{ Change Score } \\
\hline & \multicolumn{2}{|l|}{ ODI } & \multicolumn{2}{|l|}{ VAS BP } & \multicolumn{2}{|l|}{ VAS LP } \\
\hline & Mean \pm SD & $P$ & Mean \pm SD & $P$ & Mean \pm SD & $\mathrm{P}$ \\
\hline \multicolumn{7}{|l|}{ Gender } \\
\hline Male & $27.3 \pm 19.6$ & 0.98 & $36.7 \pm 30.0$ & 0.52 & $12.9 \pm 40.7$ & 0.76 \\
\hline Female & $28.5 \pm 24.4$ & & $45.5 \pm 32.3$ & & $23.7 \pm 30.1$ & \\
\hline \multicolumn{7}{|l|}{ Age } \\
\hline$>45$ & $43.4 \pm 14.7$ & $0.03^{*}$ & $27.1 \pm 35.9$ & 0.16 & $21.4 \pm 29.1$ & 0.74 \\
\hline$\leq 45$ & $22.8 \pm 22.6$ & & $47.8 \pm 27.5$ & & $20.4 \pm 35.0$ & \\
\hline \multicolumn{7}{|l|}{ Modic Changes } \\
\hline Yes & $29.4 \pm 21.0$ & 0.94 & $46.7 \pm 30.4$ & 0.49 & $23.5 \pm 33.0$ & 0.89 \\
\hline No & $26.4 \pm 21.0$ & & $38.0 \pm 25.6$ & & $26.7 \pm 23.1$ & \\
\hline \multicolumn{7}{|l|}{ Prior Surgery } \\
\hline Yes & $30 \pm 17.1$ & 0.85 & $45.3 \pm 36.4$ & 0.70 & $20.8 \pm 45.3$ & 0.93 \\
\hline No & $29.6 \pm 24.5$ & & $37.7 \pm 27.4$ & & $23.0 \pm 23.1$ & \\
\hline \multicolumn{7}{|l|}{ Discography } \\
\hline Positive & $30.8 \pm 25.4$ & 0.74 & $38.1 \pm 35.0$ & 1.00 & $12.3 \pm 28.6$ & 0.20 \\
\hline Negative & $32.0 \pm 2.0$ & & $43.3 \pm 25.2$ & & $33.3 \pm 11.5$ & \\
\hline \multicolumn{7}{|c|}{ Smoking Status } \\
\hline Smoker & $29.5 \pm 16.5$ & 0.95 & $44.4 \pm 27.7$ & 0.78 & $7.1 \pm 30.4$ & 0.10 \\
\hline Non-Smoker & $27.5 \pm 23.6$ & & $47.4 \pm 28.6$ & & $31.7 \pm 29.5$ & \\
\hline
\end{tabular}

\section{TABLE 5: Analysis of factors potentially associated with PROM change scores}

${ }^{*} \mathrm{p} \leq 0.05$

PROM, patient-reported outcome measure; SD, standard deviation; VAS, visual analogue scale; ODI, Oswestry Disability Index; MCID, minimum clinically important difference.

\section{Safety}

We observed only one complication. Postoperative radiculopathy appeared in one patient (2.3\%), but the issue resolved after six weeks. Aside from this none of the complications associated with ALIF, such as retrograde ejaculation, incisional hernia, or vascular injuries among others, were observed in this study.

\section{Discussion}

In this evaluation of a prospective registry, among 44 patients undergoing ALIF for degenerative disc disease using an ERAS protocol in a short-stay setting, efficacy, and safety was assessed. Clinical success was achieved in a considerable number of patients, yielding an overall clinical success rate of $78 \%$ at 12 months postoperatively. Complications were held to a minimum with the appearance of only one transient complication.

Previously, a series of RCTs demonstrated that - in a general patient population with CLBP - fusion surgery is no better than conservative treatment [7]. However, newer studies have shown that, while this finding certainly holds true in an unselected patient cohort, very strict patient selection can identify subsets of patients who truly profit from surgical treatment after years of unsuccessful conservative treatment [1]. Lammli et al. [4] found a significant decrease in pain and substantial functional improvements after the procedure. In addition, Kleimeyer et al. [2] found a higher efficacy in selective ALIF than in nonsurgical treatment. With the satisfactory outcomes regarding the effectiveness of the procedure that this study yielded for CLBP - a pain syndrome notoriously hard to treat - our findings coincide with the current 
literature and suggest that ALIF is effective in carefully selected patients who have failed long-term conservative treatment and when surgery is strictly considered a "last resort".

A range of prognostic tools have been tested over the years. Apart from failed long-term conservative treatment, the PCT has shown to be the single most efficient prognostic test for outcome after surgery for CLBP, and has been independently verified to be so $[1,8]$. A positive PCT is especially predictive in patients with single-level DDD without prior surgery $[1,8]$. This effect may be explained in two ways: The PCT simulates a bony fusion by stabilizing the lumbar vertebrae, and the willingness to endure an uncomfortable pantaloon cast for two weeks indicating a certain "last resort" motivation. In this study, the predictive effects of a positive PCT, according to the definitions of its positivity ( $\geqslant 50 \%$ pain reduction), was not found by the obviously insufficient power of this specific analysis since $96 \%$ of surgically treated patients had a positive PCT. In contrast, discography has failed to show prognostic value in this patient population, and deleterious effects have even been demonstrated to occur after disc infiltration [1,17-20,28].

A low occurrence of complications in ALIF procedures, along with low morbidity have been reported by various studies [2-4,29-30]. Additionally, the success and fusion rate of the procedure has been reported to be relatively high by many authors [3]. Along with reports of shorter surgery times and lower blood loss, this substantiates the safety of ALIF procedures in a subset of the general DDD population. In light of the absence of a general or vascular surgeon, or intensive care unit in most short-stay settings, the multidisciplinary approach in partnership with a general or vascular surgeon cannot be underestimated.

While there generally is a consensus of the safety and efficacy of standalone ALIF with many studies showing similar outcomes, the results should nevertheless be interpreted with caution. Several authors have questioned the superiority of posterior spinal fusion in the long run [7]. Giang et al. [30] stated in a review of the current literature that while stand-alone ALIF is generally seen as effective, some key studies showed opposite results, fortifying the existing dissent on the topic.

ERAS protocols were first developed in colorectal surgery and have since been applied in a wide range of surgical specialties [10]. In spine surgery, ERAS has been shown to reduce acute care costs, length of hospital stay, and postoperative pain [9,12-14]. The rationale of ERAS lies within the fact that its elements aim to (1) improve the preoperative state of the patient, (2) reduce the burden of surgery, and (3) stimulate fast recovery to ADL. In our series, our proprietary ERAS protocol has been applied [9]. Although neither intergroup comparison to non-ERAS patients nor comparison to a historical control group was possible, our experience underlines the importance of a multidisciplinary team to streamline the recovery process. Foremost, this is essential in a short-stay setting, where reducing the burden of surgery can lead to massive patient and financial benefits over time, especially once the initial learning curve in implementation of the ERAS protocol has been completed [9].

\section{Limitations}

This study was largely limited by the small sample size and partly incomplete data, which resulted in low statistical power. In addition, although this was not the focus of this study, the finding pertaining to prognostic factors may be less powerful due to the low sample size, and the one statistically significant finding may have been arrived at by multiple testing. However, all data stem from a prospective registry. All procedures were conducted in a single-center, which may lead to further bias. The results may not be applicable to all treatment groups since the patients were already highly selected on the grounds of a positive PCT, and hence the analysis regarding PROMs only concern subsets of the general surgical population. In a similar manner, our findings might not be applicable to older adults, since the dataset did not include patients above the age of 62 .

\section{Conclusions}

In this study, clinical success was achieved in a considerable number of patients with the occurrence of only one complication that resolved after six weeks. With these favorable outcomes, it can be suggested that standalone ALIF in a short-stay setting with application of an ERAS protocol is an effective and safe treatment for CLBP associated with DDD. Thus, it may be an option for strictly selected patients who may profit from surgery after failed long-term conservative therapy. A multidisciplinary approach, encompassing access surgery and anesthesiology, is crucially important to the procedure's safety and success in a shortstay setting.

\section{Additional Information \\ Disclosures}

Human subjects: Consent was obtained by all participants in this study. Medical Research Ethics Committees United issued approval W16.065. This institutional registry was approved by the local institutional review board (Medical Research Ethics Committees United, Registration Number: W16.065), and this study was performed according to the Declaration of Helsinki. . Animal subjects: All authors have confirmed that this study did not involve animal subjects or tissue. Conflicts of interest: In compliance with the ICMJE uniform disclosure form, all authors declare the following: Payment/services info: All 
authors have declared that no financial support was received from any organization for the submitted work. Financial relationships: All authors have declared that they have no financial relationships at present or within the previous three years with any organizations that might have an interest in the submitted work.

Other relationships: All authors have declared that there are no other relationships or activities that could appear to have influenced the submitted work.

\section{References}

1. Staartjes VE, Vergroesen PPA, Zeilstra DJ, Schröder ML: Identifying subsets of patients with single-level degenerative disc disease for lumbar fusion: the value of prognostic tests in surgical decision making. Spine J. 2018, 18:558-566. 10.1016/j.spinee.2017.08.242

2. Kleimeyer JP, Cheng I, Alamin TF, Hu SS, Cha T, Yanamadala V, Wood: KB: Selective anterior lumbar interbody fusion for low back pain associated with degenerative disc disease versus nonsurgical management. Spine. 2018, 43:1372-1380. 10.1097/BRS.0000000000002630

3. Rao PJ, Loganathan A, Yeung V, Mobbs RJ: Outcomes of anterior lumbar interbody fusion surgery based on indication: a prospective study. Neurosurgery. 2015, 76:7-23. 10.1227/NEU.0000000000000561

4. Lammli J, Whitaker MC, Moskowitz A, et al.: Stand-alone anterior lumbar interbody fusion for degenerative disc disease of the lumbar spine: results with a 2-year follow-up. Spine. 2014, 39:E894-E901. 10.1097/BRS.0000000000000393

5. Vergroesen PPA, Kingma I, Emanuel KS, et al.: Mechanics and biology in intervertebral disc degeneration: a vicious circle. Osteoarthritis Cartilage. 2015, 23:1057-070. 10.1016/j.joca.2015.03.028

6. Landi A, Gregori F, Mancarella C, Maiola V, Maccari E, Marotta N, Delfini R: Lumbar spinal degenerative microinstability: hype or hope? Proposal of a new classification to detect it and to assess surgical treatment. Eur Spine J. 2015, 24:872-878. 10.1007/s00586-015-4274-6

7. Mannion AF, Brox JI, Fairbank JC: Consensus at last! Long-term results of all randomized controlled trials show that fusion is no better than non-operative care in improving pain and disability in chronic low back pain. Spine J. 2016, 16:588-590. 10.1016/j.spinee.2015.12.001

8. Willems PC, Elmans L, Anderson PG, Jacobs WCH, Schaaf DBVD, de Kleuver M: The value of a pantaloon cast test in surgical decision making for chronic low back pain patients: a systematic review of the literature supplemented with a prospective cohort study. Eur Spine J. 2006, 15:1487-1494. 10.1007/s00586-006-0121-0

9. Staartjes VE, de Wispelaere MP, Schröder ML: Improving recovery after elective degenerative spine surgery: 5-year experience with an enhanced recovery after surgery (ERAS) protocol. Neurosurg Focus. 2019, 46:7-7. 10.3171/2019.1.FOCUS18646

10. Ljungqvist O, Scott M, Fearon KC: Enhanced recovery after surgery: a review . JAMA Surg. 2017, 152:292298. 10.1001/jamasurg.2016.4952

11. Wang MY, Chang PY, Grossman J: Development of an Enhanced Recovery After Surgery (ERAS) approach for lumbar spinal fusion. J Neurosurg Spine. 2017, 26:411-418. 10.3171/2016.9.SPINE16375

12. Corniola MV, Debono B, Joswig H, Leme JM, Tessitore E: Enhanced recovery after spine surgery: review of the literature. Neurosurg Focus. 2019, 46:2-2. 10.3171/2019.1.FOCUS18657

13. Ali ZS, Ma TS, Ozturk AK, et al.: Pre-optimization of spinal surgery patients: development of a neurosurgical enhanced recovery after surgery (ERAS) protocol. Clin Neurol Neurosurg. 2018, 164:142-153. 10.1016/j.clineuro.2017.12.003

14. Wainwright TW, Immins T, Middleton RG: Enhanced recovery after surgery (ERAS) and its applicability for major spine surgery. Best Pract Res Clin Anaesthesiol. 2016, 30:91-102. 10.1016/j.bpa.2015.11.001

15. von Elm E, Altman DG, Egger M, Pocock SJ, Gøtzsche PC, Vandenbroucke JP: Strengthening the reporting of observational studies in epidemiology (STROBE) statement: guidelines for reporting observational studies. BMJ. 2007, 335:806-808. 10.1136/bmj.39335.541782.AD

16. Willems PC, Staal JB, Walenkamp GHIM, de Bie RA: Spinal fusion for chronic low back pain: systematic review on the accuracy of tests for patient selection. Spine J. 2013, 13:99-109. 10.1016/j.spinee.2012.10.001

17. Alamin TF, Kim MJ, Agarwal V: Provocative lumbar discography versus functional anesthetic discography: a comparison of the results of two different diagnostic techniques in 52 patients with chronic low back pain. Spine J. 2011, 11:756-765. 10.1016/j.spinee.2011.07.021

18. Carragee EJ, Lincoln T, Parmar VS, Alamin T: A gold standard evaluation of the discogenic pain diagnosis as determined by provocative discography. Spine. 2006, 31:21-15. 10.1097/01.brs.0000231436.30262.dd

19. Cuellar JM, Stauff MP, Herzog RJ, Carrino JA, Baker GA, Carragee EJ: Does provocative discography cause clinically important injury to the lumbar intervertebral disc? A 10-year matched cohort study. Spine J. 2016, 16:273-280. 10.1016/j.spinee.2015.06.051

20. Putzier M, Streitparth F, Hartwig T, Perka CF, Hoff EK, Strube P: Can discoblock replace discography for identifying painful degenerated discs?. Eur J Radiol. 2013, 82:1463-1470. 10.1016/j.ejrad.2013.03.022

21. Willems PC, Elmans L, Anderson PG, van der Schaaf B, de Kleuver M: Provocative discography and lumbar fusion: is preoperative assessment of adjacent discs useful?. Spine. 2007, 32:1094-1099. 10.1097/01.brs.0000261672.97430.b0

22. Mazmudar A, Minhas S, Mayo BC, Massel DH, Patel A: Outcomes and safety of outpatient spinal surgery in adult patients older than 65. Contemp Spine Surg. 2016, 17:1-5. 10.1097/01.CSS.0000504611.56487.40

23. Siccoli A, Staartjes VE, de Wispelaere MP, Schröder ML: Is elective degenerative lumbar spine surgery in older adults safe in a short-stay clinic? Data from an institutional registry. Eur Geriatr Med. 2019, 10:79-88. 10.1007/s41999-018-0132-5

24. Saklad M: Grading of patients for surgical procedures. J Am Soc Anesthesiol. 1941, 2:281-284.

25. Nielsen BR, Abdulla J, Andersen HE, Schwarz P, Suetta C: Sarcopenia and osteoporosis in older people: a systematic review and meta-analysis. Eur Geriatr Med. 2018, 9:419-434. 10.1007/s41999-018-0079-6

26. Jegede KA, Buckland AJ, Delsole EM, Zhou PL, Vasquez-Montes D, Goldstein JA, Bendo JA: The use of cell saver in spinal surgery: a value-based utilization analysis. Spine J. 2017, 17:201.

10.1016/j.spinee.2017.07.288

27. Staartjes VE, Siccoli A, de Wispelaere MP, Schröder ML: Patient-reported outcomes unbiased by length of 


\section{Cureus}

follow-up after lumbar degenerative spine surgery: do we need 2 years of follow-up?. Spine J. 2018,

10.1016/j.spinee.2018.10.004

28. Ohtori S, Kinoshita T, Yamashita M, et al.: Results of surgery for discogenic low back pain: a randomized study using discography versus discoblock for diagnosis. Spine. 2009, 34:1345-1348.

10.1097/BRS.0b013e3181a401bf

29. Pinson H, Hallaert G, Herregodts P, et al.: Outcome of anterior lumbar interbody fusion: a retrospective study of clinical and radiologic parameters. World Neurosurg. 2017, 103:772-779. 10.1016/i.wneu.2017.04.077

30. Giang G, Mobbs R, Phan S, Tran TM, Phan K: Evaluating outcomes of stand-alone anterior lumbar interbody fusion: a systematic review. World Neurosurg. 2017, 104:259-271. 10.1016/i.wneu.2017.05.011 